\title{
Vietnamese Consumers' Intention to Use Online Shopping: The Role of Trust
}

\author{
Thi Huong Lan $\mathrm{Ho}^{1,2}$ \& Yizeng Chen ${ }^{1}$ \\ ${ }^{1}$ School of Management, Shanghai University, Shanghai City, China \\ ${ }^{2}$ College of Economics, Hue University, Hue City, Vietnam \\ Correspondence: Thi Huong Lan Ho, School of Management, Shanghai University, 99 Shangda Road, Baoshan \\ District, 200444, China. E-mail: huonglanmarketing@gmail.com
}

\author{
Received: February 26, 2014 \\ Accepted: April 8, $2014 \quad$ Online Published: April 18, 2014 \\ doi:10.5539/ijbm.v9n5p145 \\ URL: http://dx.doi.org/10.5539/ijbm.v9n5p145
}

\begin{abstract}
Because of online shopping characterized by facelessness and intangibility, consumers are often reluctant to engage in any forms of online transactions (Grabner-Kräuter \& Kaluscha, 2003). Accordingly, trust has played a significant role and been considered as a consumers' essential condition to engage in E-commerce. The key objective of this study is to examine the role of trust in Vietnamese consumers' intention to use online shopping through empirically testing the integrated model of trust perspectives which are technology beliefs, trusting beliefs (consumers' trust in online shopping) and subjective norm beliefs. The result of this study indicates that $64.2 \%$ variance of consumers' intention to use online shopping is explained by technology beliefs, trusting beliefs and subjective norm beliefs among which, technology beliefs (typically is perceived usefulness) is the strongest influencing factor and is followed by trusting beliefs (typically is integrity of online vendor). Notably, this study also admits the role of subjective norm beliefs and their impact on Vietnamese consumers' intention to shop online. The findings of this study are noteworthy for both researchers and practitioners because of its contribution to theoretical and empirical perspectives.
\end{abstract}

Keywords: online shopping, trust, technology beliefs, trusting beliefs, subjective norm beliefs, and consumers' intention

\section{Introduction}

E-commerce has been proliferating rapidly all around the world and positively known as a new form of business, in which the sale of products and services are performed over the Internet. E-commerce, which is typicalized by online shopping, enables consumers to shop or do transactions 24 hours a day, all year around from almost any locations. It also provides consumers more choices and allows them to have quick comparisons. Moreover, it allows consumers to interact, exchange ideas, and compare experiences with other customers in the electronic communities (Ahn, Ryu et al., 2004). As a result, e-commerce landscape has gradually been characterized by very high competition and the marketplace is changing at a very dynamic pace where online consumers are increasingly looking for enjoyment and excitement in their shopping experience (Jayawardhena \& Wright 2009).

Nevertheless, differing from traditional brick and mortar environment where transactions are made mainly based on personal relationships and face-to-face interactions between the consumer and the merchant, online shopping characterized by facelessness and intangibility is plagued with a host of concerns such as uncertainty, anonymity, lack of control and potential opportunism which could result in consumers' reluctance to engage in any forms of online transactions (Grabner-Kräuter \& Kaluscha, 2003). Many evidences suggested that consumers often exchange hesitatingly with online vendors due to their uncertainty of the partner's behavior or their awareness of the risk of stolen personal information. Hence, trust has been considered as a consumers' essential condition to engage in E-commerce. Trust has played a central role in helping consumers overcome the perceived risk and security in online shopping. Furthermore, trust makes consumers share comfortably their personal information, make transactions and act follow the supplier's advices all of which are considered as the essential actions for consumers to adopt e-commerce widely (McKnight et al., 2002). It can be seen that success of an online business firm mainly rests on many factors among which trust is one of the most important contributors.

Accordingly, the main purpose of this study is to develop and test a model that enhances our understanding of 
how the role of trust affects Vietnamese consumers' intention to adopt online shopping. Specifically, based on the integrated model of trust perspectives which are technology beliefs, consumers' trust in online shopping (trusting beliefs), and subjective norm beliefs, this study tries to explain how Vietnamese consumers' intention to adopt online shopping is affected by trust. The effect of the predictors can be interpreted as the reasons why consumers intend to shop online.

We expect that this study will present important theoretical and practical contributions. Theoretically, we develop an integrated model of consumer trust in Internet shopping by synthesizing three different theoretical perspectives which are technology, business and social norm. Furthermore, the scales developed will provide a useful tool, enabling better understanding of Vietnamese shoppers' current and potential future shopping behavior in the online environment. Practically, it is expected that we will identify the important factors of trust affecting Vietnamese consumers' intention to online shopping adoption. The results provide Internet vendors some guidelines to build Vietnamese consumers' trust and enhance the exchanging relationships with Internet shoppers.

\section{Theoretical Foundation}

The study's theoretical foundation is based on several prominent theories that address online shopping adoption and the role of trust in consumers' acceptance to the use of purchasing via the Internet.

To clarify the role of Vietnamese consumers' trust in adopting online shopping, this paper used the combination of three theories including Technology acceptance model (TAM), customer trust in online shopping and social norm (Davis, 1989; Venkatesh \& Davis 2000; Venkatesh \& Morris, 2000; Gefen et al., 2003; Holsapple \& Sasidharan, 2005) as a useful theoretical foundation to explain the aspects of Vietnamese consumers' beliefs affecting their behavioral intention to engage in online shopping. In the framework of this theory, "online shopping" is defined as consumers' use of online stores from the stage of purchase to logistics. Theoretically, the proposed concepts of trust in the above model are understood as follows.

\subsection{The Technology Acceptance Model (TAM)}

TAM proposes that two beliefs (technology beliefs) about a new technology, perceived usefulness and perceived ease of use, determine a person's attitude toward using that technology, which in turn determines their intention to use it. Perceived usefulness (PU) is the degree to which one believes that using the technology will enhance his/her performance. Perceived ease of use (PEOU) is the degree to which one believes that using the technology will be free of effort (Davis 1989). In some previous researches on E-commerce (Venkatesh and Davis 2000; Venkatesh, Morris et al. 2003; Ha and Stoel 2009), TAM provides a useful foundation for research investigating consumer acceptance of online shopping.

\subsection{Consumers' Trust in Online Shopping (Trusting Beliefs)}

Consumers' trust in online shopping can be interpreted as trust in a specific object such as trust in e-commerce or trust in online vendor. According to McKnight et al. (2001): "Trusting beliefs mean one believes (and feels confident in believing) that the other person has one or more traits desirable to one in a situation in which negative consequences are possible". Trusting beliefs can be seen as reliability and trustworthiness of the e-vendors supplying products or services. Some previous studies have used most often three trusting beliefs as antecedents of consumers' trust in online vendor: competence (ability of the trustee to do what the truster needs), benevolence (trustee caring and motivation to act in the truster's interests), and integrity (trustee honesty and promise keeping) (McKnight et al., 2002)

\subsection{Social Norm Beliefs}

Social influence has been considered as a significant antecedent of behavior intention to use an innovation (Venkatesh et al. 2003). It is conceptualized in terms of the social pressure that individual's perception from referent important others to do or not to do a behavior (social norm beliefs). In another words, social influence inspired by subjective norm (SN) defining as "the degree to which an individual believes that people who are important to her/him think she/he should perform the behavior in question"(Venkatesh \& Morris 2000). Subjective norm is a function of normative beliefs and is determined by social norm beliefs about the extent to which significant referents want them to approve a behavior (Rivis \& Sheeran, 2003). Through reviewing of the online shopping literature, it is suggested that the social influence is derived from both internal influence (family, friends and colleagues...) and external influence (Television Ad programs, social network, meadia...) (Çelik, 2011).

From the review of related prior literatures and empirical studies explaining consumers' intention to adopt online shopping, a conceptual framework of this study is proposed from the belief theories integration on three aspects: 
technology beliefs, trusting beliefs and subjective norm beliefs explaining by the following reasons:

Firstly, TAM, used to explain the usage behavior of a new technology, is determined by individual's attitude in using this technology. Many previous researches proposed the validity of TAM as a model for explaining attitude and intention to adopt technology related to different contexts. Nonetheless, the variables in TAM (Perceived ease of use and Perceived usefulness) are only suitable to explain the decisions regarding the choice of using technology rather than that of users' voluntary choice situations (Vijayasarathy, 2004).

Secondly, it can be seen that the variables in TAM cannot fully grasp the important beliefs affecting consumers' attitude towards online shopping (Ha \& Stoel, 2009). TAM explains the influence of consumers' beliefs in using technology, however, the positive perception of the technology itself is not enough to encourage consumers to visit websites and to shop on the e-stores (Benamati et al., 2010). Moreover, several recent studies suggested that in the online shopping process, the main factors limiting the adoption to online shopping are security and trust (Gefen, 2000; Cheung \& Lee, 2003). This implies that the lack of consumers' trust in online shopping leads to a big psychological barrier to consumers' intention to adopt e-commerce.

Lastly, TAM has been criticized for ignoring social influence on technology acceptance (Moon \& Kim, 2001; Chen \& Chang, 2003). Simultaneously, in several studies on technology adoption, social factors, especially the subjective norms, have been concerned as a key determinant to behavioral intention to use a specific technology (Venkatesh et al., 2003).

\section{Research Model and Proposed Hypotheses}

Taken from prior researches examining the role of consumers' trust towards their intention to adopt online shopping and combined with the result of a qualitative study conducted in the context of online shopping in Vietnam (Ho \& Chen, 2013), a proposed conceptual model was developed to guide examination of the adoption of online shopping and the impact of consumers' trust on internet purchase adoption intentions. Synthesizing the three aspects of consumers' trust in online shopping, a research model with a variety of factors specific to the context of Internet shopping is postulated (see in Figure 1).

Internet shopping is a new kind of commercial transaction where consumers' interaction with online stores and their experience are completely different from the mortar and brick shopping (Cheung \& Lee, 2003). In the online shopping environment, due to the distance, virtual awareness and lack of E-commerce's regulation, consumers are often more aware of the risk to shop on the Internet than that of conventional shopping environment (Corbitt et al., 2003). Many evidences suggested that consumers often exchange hesitatingly with online vendors due to their uncertainty of the partner's behavior or their awareness of the risk of stolen personal information. Hence, trust has been considered as a consumers' essential condition to engage in E-commerce. Trust has played a central role in helping consumers overcome the perceived risk and security in online shopping. With the guidance of the theoretical framework, we addressed some proposed hypotheses relying on the antecedents of consumers' trust to adopt online shopping as shown in Figure 1.

\subsection{Technology Beliefs}

Technology beliefs proposed in TAM are the Perceived usefulness and Perceived easy of use aiming at determining a person's attitude towards the technology usage, which in turn will determine consumers' intention to use that technology. Thus, the two factors of technology beliefs regarded as the core concepts in TAM are used to explain users' attitude and behavioral intention to that technology (Davis, 1989; Venkatesh \& Davis, 2000); In recent studies in the context of online shopping (Venkatesh \& Bala, 2008; Ha \& Stoel, 2009; Çelik \& Veysel, 2011), it has been shown that the relations between PEOU, PU, attitudes and intentions are in significant existence.

Hypothesis 1. PEOU positively affects attitudes toward online shopping.

Hypothesis 2. PU positively affects attitudes toward online shopping.

Hypothesis 3. Attitude towards online shopping positively affects behavioral intention to shop online.

Besides, the discussion result of some prior studies (Gefen et al. 2003; Koufaris \& Hampton-Sosa, 2004; Pavlou \& Fygenson, 2006) has shown the existence of a relationship between trust and TAM beliefs. It has been found that there is a positive relation between user's trust and PU and PEOU (Corbitt et al., 2003; Kim, Ferrin et al., 2008).

Hypothesis 4. PEOU positively affects trusting attitudes towards online shopping.

Hypothesis 5. PU positively affects trusting attitudes towards online shopping. 


\subsection{Trusting Beliefs}

Clearly trusting belief is a complicated and multidimensional structure. Differing from their trust in conventional shopping, consumers have a lower level of trust in the virtual shopping environment. In essence, consumers simply do not trust most Web providers enough to engage in relationship exchanges with them. It is witnessed that trust plays an important role and hence increases in the level of trust directly and positively affect trusting attitudes which in turn impact on the intention for e-shopping (Chen \& Dhillon, 2003).

Hypothesis 6. Ability positively affects trusting attitudes towards online shopping.

Hypothesis 7. Integritypositively affects trusting attitudes towards online shopping.

Hypothesis 8. Benevolence positively affects trusting attitudes towards online shopping.

Hypothesis 9. Trusting attitudes in online shopping positively affect attitudes towards online shopping.

Hypothesis 10. Trusting attitudes in online shopping positively affect behavioral intention to shop online.

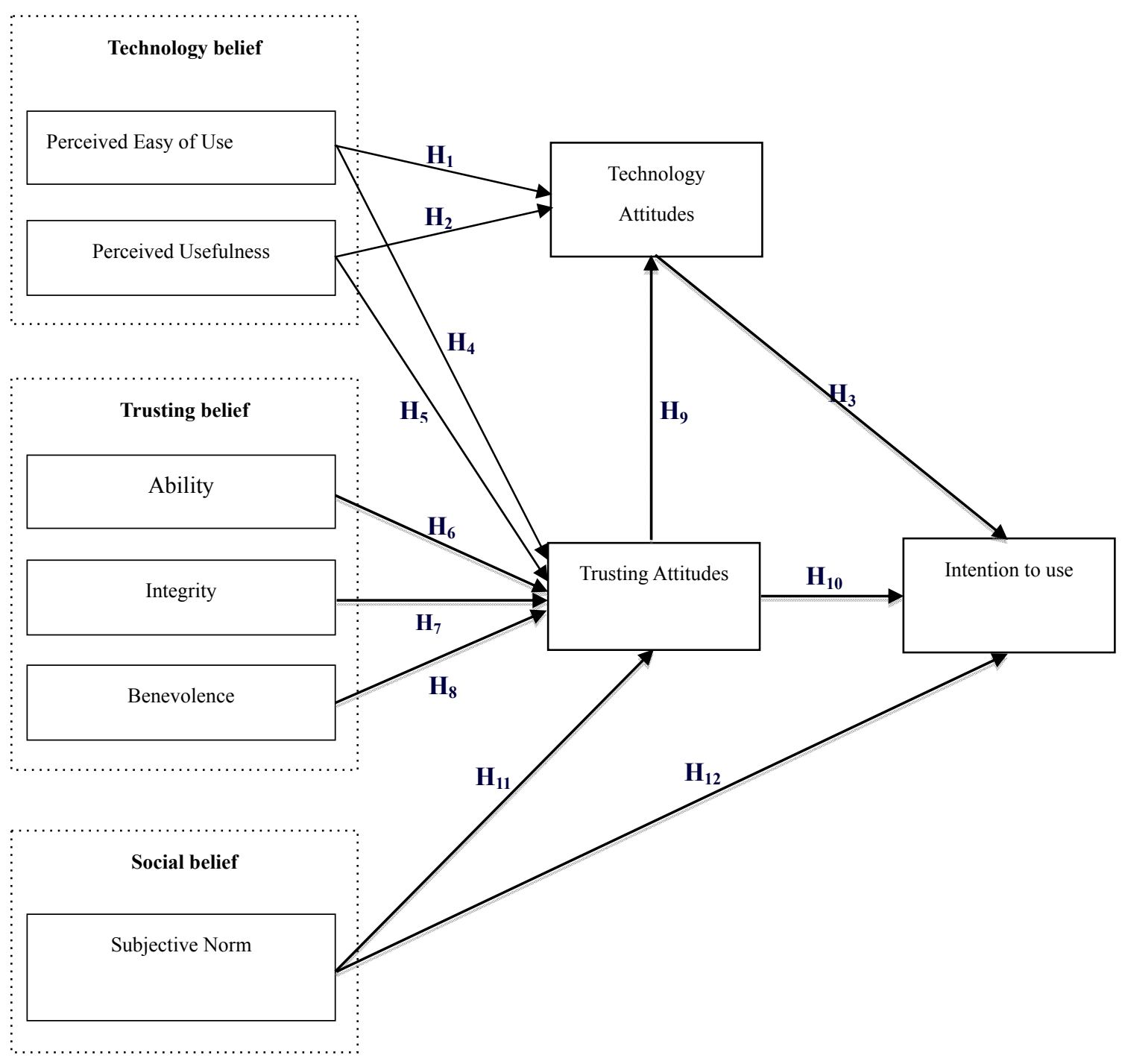

Figure 1. The research model and hypotheses

\subsection{Subjective Norm Beliefs}

Many studies have replicated, extended, and used TAM with an aim to explain the role of subjective norm towards behavior intention to usage information technology. It was found that the subjective norm has had a 
mixed and inconclusive role. Practically, subjective norm was found to have considerable impacts on the consumers' behavioral intention in some previous studies; however, others did not find significant effects (Schepers \& Wetzels, 2007). From the result of a qualitative research conducted in the context of online shopping in Vietnam, it is explored that subjective norm has affected consumers' trusting attitude towards online vendor and their behavioral intention to use online shopping as well (Ho \& Chen, 2013). Accordingly, two following hypotheses related are proposed in this study:

Hypothesis 11. Subjective norm positively affects trusting attitudes towards online shopping.

Hypothesis 12. Subjective norm positively affects behavioral intention to shop online.

\section{Survey Development and Administration}

\subsection{Measurement Development}

To develop the questionnaire, the multiple-item method was used and each item was measured based on a five-point Likert type scale (ranging from $1=$ strongly disagree to $5=$ strongly agree). More specifically, our study adapted the measures used to operationalize the constructs embedding in proposed theoretical model from relevant previous studies in the context of online shopping. Items from constructs of perceived ease of use; perceived usefulness; attitude towards online shopping and behavioral intention were revised from Ahn (Ahn et al. 2007). The measures of ability, integrity and benevolence were adapted from Gefen and McKnight (Gefen 2002; McKnight et al., 2002) while items for measuring trusting attitudes were adapted from Benamati and Fuller (Benamati et al., 2010). Items for subjective norms were revised from Lin (Lin 2008). From adapting these measures, we made minor wording changes to tailor these measures to Vietnamese online shoppers' perception and understanding (see appendix).

\subsection{Data Collection}

In order to test the above-proposed model, a national online survey was used to collect data for empirical testing by using both convenient sampling and snow - ball techniques. The unit of analysis in this study is the individual consumer who has experienced buying products and service via the Internet. This online data collection method was also in consistent with the research subjects of the study, online buyers. We distributed the link through the survey website www.manual.limesurvey.org. The online shoppers were invited by receiving the invitation letter via e-mail to follow this link to the survey, which took approximately 15-20 minutes to finish. Most of the participants were volunteers who are interested in such a research topic and have experienced online shopping before. Descriptive statistics of the respondent profile are shown in Table 1.

\subsection{Statistical Analysis}

Data analysis was carried out in accordance with the use of the structural equation modeling (SEM) approach, supported by Amos 20.0 software with maximum likelihood estimation (Lei \& Wu, 2007). Following the two stage model building process for SEM, the measurement model first is developed and then evaluated separately from the full structural equation model (Gefen et al., 2003). Accordingly, the measurement model was estimated using confirmatory factor analysis (CFA) to test its reliability and validity and the structural model was also analyzed to examine whether the model would fit results of the proposed theoretical models.

To assess model fit, we used the chi-square to degrees of freedom ratio (chisq-df-ratio), the comparative fit index (CFI), residual mean squared error of approximation (RMSEA), and root mean squared residual (RMR). For CFI, values above 0.90 indicate good model fit. As for RMSEA and RMR, their values below 0.05 for each indicate close fit, while values below 0.08 indicate an adequate fit (Browne et al., 1993).

More specification, as this study does not directly examine relationship between technology beliefs, trusting beliefs as well as subjective norm beliefs and intention to use online shopping, technology attitudes and trusting attitudes play a mediating role affecting intention to shop online in the model. The study also continuously analyze that the mediating role of technology attitudes and trusting attitudes are indeed crucial to better understand intentions because attitudes act as an intermediary between beliefs and behavioral intentions. 
Table 1. Sample characteristics $(\mathrm{n}=597)$

\begin{tabular}{|c|c|c|c|}
\hline Demographic characteristics & Frequency & Percent (\%) & Cumulative (\%) \\
\hline \multicolumn{4}{|l|}{ * Gender } \\
\hline Male & 242 & 40.5 & 40.5 \\
\hline Female & 355 & 59.5 & 100 \\
\hline \multicolumn{4}{|l|}{$*$ Age } \\
\hline$<25$ years old & 112 & 18.8 & 18.8 \\
\hline $25-35$ years old & 411 & 68.8 & 87.6 \\
\hline $35-45$ years old & 74 & 12.4 & 100 \\
\hline \multicolumn{4}{|c|}{ * Online shopping experience (year) } \\
\hline$<1$ year & 150 & 25.1 & 25.1 \\
\hline $1-2$ years & 178 & 29.8 & 54.9 \\
\hline $2-3$ years & 111 & 18.6 & 73.5 \\
\hline$>3$ years & 158 & 26.5 & 100 \\
\hline \multicolumn{4}{|l|}{ * Frequency of online shopping } \\
\hline$<$ One time per week & 4 & 0.7 & 0.7 \\
\hline One time per week & 63 & 10.6 & 11.3 \\
\hline 2-3 times per month & 134 & 22.4 & 33.7 \\
\hline One time per month & 86 & 14.4 & 48.1 \\
\hline $2-3$ months/ time & 174 & 29.1 & 77.2 \\
\hline 2-3 times per year & 117 & 19.6 & 96.8 \\
\hline Over than one time per year & 19 & 3.2 & 100 \\
\hline
\end{tabular}

\section{Results and Discussion}

\subsection{Evaluating the Measurement Model}

A confirmatory factor analysis (CFA) was conducted on the nine variables measured by multi-item scales. Results exhibited a significant chi-square statistic (chi-square $\chi^{2} \_2942.897$; df_819; p-value_.000) indicating that the model did not show a perfect fit to the data. However, for incremental fit measure, both Comparative Fit Index (CFI_.918) and Tucker-Lewis Index (TLI_.909) in this study are greater than the .90 recommended. As for other important fit indexes, Root Mean Square Error of Approximation (RMSEA_.066) exceeded the recommended cut-off level of .08 for a good fit and Root mean squared residual (RMR_.045) was lower than 0.05 for an excellent fit (Browne, Cudeck et al. 1993). The combination of these results, thereby, provided evidence that the demonstrated measurement model fits the data well.

Next, to reflect the strength of the measurement model, convergent and discriminant validity of all constructs are considered to assess. At first, convergent validity of a construct is the degree to which multiple attempts to measure the same concept are in agreement. This study used three tests to assess convergent validity: constructs' reliability, composite reliability of constructs, and average variance extracted by constructs (Schreiber et al., 2006). Cronbach's alpha and factor loading in CFA result are two common criteria used in order to assess reliability of constructs. As shown intable 2, the cronbach's alpha coefficients highly ranged from 0.896 to 0.948 for all constructs, which were above the recommended threshold of 0.70 (Nunnally \& Bernstein, 1991). The factor loading for all items in this study significantly ranged from .577 to .971 exceeding the recommended level of .5 (Hair et al., 1998). This result provided an evidence of adequate reliability of the measures. In addition, the composite reliability of all latent constructs highly located in .865-.934 exceeding the criterion of .7 (Hair et al., 1998). Therefore, composite reliability of the measurement model was also good. For the average variances extracted by measures, it reflects the overall amount of variance in the indicators accounted for by the latent construct with a score of .5 indicates acceptability (Fornell and Larcker 1981). The result in table 2 showed that the average variances extracted of all latent constructs were in the range between .63 and .776 . It revealed that all constructs in this study have adequate convergent validity. 
Table 2. Results of CFA for measurement model

\begin{tabular}{|c|c|c|c|c|c|}
\hline \multirow[b]{2}{*}{ Constructs } & \multirow[b]{2}{*}{ Items } & \multirow{2}{*}{$\begin{array}{l}\text { Internal } \\
\text { Reliability } \\
\text { Cronbach's } \\
\text { alpha } \\
\end{array}$} & \multirow[b]{2}{*}{$\begin{array}{l}\text { Standardized } \\
\text { factor loading }\end{array}$} & \multicolumn{2}{|c|}{ Convergent validity } \\
\hline & & & & $\begin{array}{l}\text { Composite } \\
\text { reliability (a) }\end{array}$ & $\begin{array}{l}\text { Average } \\
\text { Variance } \\
\text { Extracted (b) }\end{array}$ \\
\hline \multirow{3}{*}{ PERCEIVED EASY OF USE } & PEOU1 & & .884 & & \\
\hline & PEOU2 & & .844 & & \\
\hline & PEOU3 & .922 & .840 & .922 & .747 \\
\hline \multirow{5}{*}{ PERCEIVED USEFULNESS } & PEOU4 & & .889 & & \\
\hline & PU1 & & .786 & & \\
\hline & PU2 & & .760 & & \\
\hline & PU3 & .896 & .775 & .898 & .639 \\
\hline & PU4 & & .823 & & \\
\hline \multirow{5}{*}{ ABILITY } & PU5 & & .852 & & \\
\hline & ABI1 & & .842 & & \\
\hline & ABI2 & & .852 & & \\
\hline & $\mathrm{ABI} 3$ & .938 & .829 & .934 & .705 \\
\hline & $\mathrm{ABI} 4$ & & .781 & & \\
\hline \multirow{7}{*}{ INTEGRITY } & ABI5 & & .862 & & \\
\hline & ABI6 & & .872 & & \\
\hline & INT1 & & .875 & & \\
\hline & INT2 & & .918 & & \\
\hline & INT3 & .93 & .880 & .925 & .714 \\
\hline & INT4 & & .774 & & \\
\hline & INT5 & & .769 & & \\
\hline \multirow{4}{*}{ BENEVOLENCE } & BEN1 & & .825 & & \\
\hline & BEN2 & & .852 & & \\
\hline & BEN3 & .93 & .876 & .928 & .723 \\
\hline & BEN4 & & .861 & & \\
\hline \multirow{5}{*}{ SUBJECTIVE NORMS } & BEN5 & & .837 & & \\
\hline & RG1 & & .679 & & \\
\hline & RG2 & & .705 & & \\
\hline & RG3 & .907 & .950 & .887 & .579 \\
\hline & RG4 & & .971 & & \\
\hline & RG5 & & .586 & & \\
\hline & RG6 & & .577 & & \\
\hline & ATT1 & & .800 & & \\
\hline \multicolumn{6}{|l|}{ TECHNOLOGY } \\
\hline \multirow{5}{*}{ ATTITUDES } & ATT2 & .941 & .861 & .942 & .766 \\
\hline & ATT3 & & .920 & & \\
\hline & ATT4 & & .885 & & \\
\hline & ATT5 & & .907 & & \\
\hline & TRU1 & & .938 & & \\
\hline \multirow[t]{3}{*}{ TRUSTING ATTITUDES } & TRU2 & .948 & .943 & .908 & .768 \\
\hline & TRU3 & & .899 & & \\
\hline & INTEN1 & & .849 & & \\
\hline \multirow{3}{*}{$\begin{array}{lcc}\text { INTENTION } & \text { TO } & \text { USE } \\
\text { ONLINE SHOPPING } & \end{array}$} & INTEN2 & .902 & .912 & .895 & .682 \\
\hline & INTEN3 & & .728 & & \\
\hline & INTEN4 & & .805 & & \\
\hline
\end{tabular}

Note. All t-value are significant at $\mathrm{p}<.001$.

(a) Composite reliability $=$ (square of the summation of the factor loadings $) /\{$ (square of the summation of the factor loadings $)+$ (summation of error variances) $\}$.

(b) Average variance extracted $=$ (summation of the square of the factor loadings $) /$ \{summation of the square of 
the factor loadings $\}+($ summation of error variances $)\}$.

Table 3. Discriminant Validity of constructs

\begin{tabular}{|c|c|c|c|c|c|c|c|c|c|}
\hline Constructs & 1 & 2 & 3 & 4 & 5 & 6 & 7 & 8 & 9 \\
\hline 1. PEOU & .639 & & & & & & & & \\
\hline 2. PU & .478 & .747 & & & & & & & \\
\hline 3. ABILITY & .426 & .510 & .705 & & & & & & \\
\hline 4. INTEGRITY & .209 & .525 & .615 & .714 & & & & & \\
\hline 5. BENEVOLENCE & .245 & .495 & .615 & .318 & .723 & & & & \\
\hline 6. SUBECTIVE NORMS & .117 & .117 & .115 & .090 & .062 & .579 & & & \\
\hline 7. TECH. ATTITUDES & .262 & .409 & .249 & .244 & .231 & .146 & .766 & & \\
\hline 8. TRUST. ATTITUDES & .181 & .406 & .446 & .586 & .525 & .216 & .311 & .768 & \\
\hline 9. INTENTION TO USE & .303 & .582 & .364 & .327 & .346 & .278 & .740 & .492 & .682 \\
\hline
\end{tabular}

Note. Diagonals represent the average variance extracted, while the other matrix entries represent the square correlation.

Secondly, discriminant validity refers to the extent to which the measure of each construct is distinct from one another. It can be examined by comparing the squared correlations between constructs and variance extracted for a construct. Evidence about discriminant validity of the measures can be verified when the average variance extracted for each construct is higher than its correlations with all other constructs (Fornell \& Larcker, 1981). As shown in Table 3, the correlations among constructs listed with the average variance extracted on the diagonal was an evidence indicating that all diagonal elements were larger than inter-construct correlations; hence discriminant validity was proved. Moreover, discriminant validity was confirmed through a confidence interval test. Confidence intervals of correlations between latent constructs were tested through the bootstrapping method using AMOS 20.0. The result showed that all intervals of the correlation are significantly less than 1.0 with the P-value .000 . The analysis results witnessed that the measure has adequately discriminant validity. In sum, the demonstrated measurement model is of adequate reliability, convergent validity and discriminant validity.

\subsection{Evaluating the Structural Model}

Given an adequate measurement model, the hypotheses could be tested by examining the structural model. To assess the structural model fit, this study estimated path coefficients in the proposed research model. The path coefficients of hypothesized relationships were calculated through the maximum likelihood technique. The explanatory power of the structural model was assessed based on the amount of variance in the endogenous construct for which the model could account.

Referring to the corresponding recommended values all fit indices achieved a good model fit: $\chi^{2}{ }_{-} 3003.243$ (p-value_.000); df = 827; RMSEA_.066; RMS_.052; CFI_.916; TLI_.908;). The explanatory power of the research model was shown in Figure 2 in which the model of behavioral intention to use online shopping, technology attitudes and trusting attitudes account for $64.2 \%$; $20.6 \%$ and $39.1 \%$ of variance $\left(\mathrm{R}^{2}\right)$, respectively. The estimated path coefficients of the structural model shown in Table 4 indicated that eight out of twelve paths were significant among which seven exhibited a p-value of .001 and one remained with a significant level of .05 . Four paths in this study "ability $\rightarrow$ trusting attitudes, benevolence $\rightarrow$ trusting attitudes, PEOU $\rightarrow$ technology attitudes, PEOU $\rightarrow$ trusting attitudes" were identified to be insignificant indicating that the hypotheses $\mathrm{H}_{1}, \mathrm{H}_{4}$, $\mathrm{H}_{6}$, and $\mathrm{H}_{8}$, were rejected (see in Table 4 and Figure 2).

In order to basically clarify the role of trust to Vietnamese consumers' intention to use online shopping, this study continuously established test for mediating effect of technology attitudes and trusting attitudes relying on the relationship between perceived usefulness, integrity as well as subjective norms and intention to shop online. This procedure firstly requires that the independent variable be significantly related to the dependent variable. Next, the test for mediating role of technology attitudes and trusting attitudes was conducted on the parsimony model (after dropping some insignificant relationships out). The testing result has provided all fit indices achieved a better model fit: $\chi^{2}{ }_{1} 1058.105$ (p-value_.000); $\mathrm{df}=333$; RMSEA_.060; RMS_.047; CFI_.955; TLI_949). The explanatory power of the research model of behavioral intention to use online shopping accounted for $69.6 \%$ of variance. Besides, it is indicated that both the relationship between perceived usefulness and intention to use as well as integrity and intention to shop online are significant with the $\beta_{-} .308$ (p-value 0.000 ) and $\beta_{-}-.127$ (p-value_0.002), respectively. The effect level of perceived usefulness, integrity and 
subjective norms to intention to use online shopping are shown inTable 5.

Table 4. Results of structural model analysis

\begin{tabular}{llllll}
\hline \multicolumn{1}{c}{ Paths } & $\begin{array}{l}\text { Standar-di } \\
\text { zed }\end{array}$ & S.E & C.R & P & Conclusion \\
& Estimate & & & & \\
\hline PEOU $\rightarrow$ Technology Attitudes ${ }^{\text {ns }}$ & .087 & .043 & 1.897 & .058 & Unsupported \\
$\mathrm{PU} \rightarrow$ Technology Attitudes $* * *$ & .313 & .059 & 6.058 & .000 & Supported \\
$\mathrm{ABI} \rightarrow$ Trusting Attitudes ${ }^{\mathrm{ns}}$ & .087 & .052 & 1.661 & .097 & Unsupported \\
$\mathrm{INT} \rightarrow$ Trusting Attitudes ${ }^{* * *}$ & .375 & .088 & 5.100 & .000 & Supported \\
$\mathrm{BEN} \rightarrow$ Trusting Attitudes ${ }^{\mathrm{ns}}$ & .111 & .071 & 1.571 & .116 & Unsupported \\
$\mathrm{PEOU} \rightarrow$ Trusting Attitudes ${ }^{\mathrm{ns}}$ & -.031 & .036 & -.721 & .471 & Unsupported \\
$\mathrm{PU} \rightarrow$ Trusting Attitudes* & .113 & .051 & 2.293 & .022 & Supported \\
$\mathrm{SN} \rightarrow$ Trusting Attitudes $* * *$ & .155 & .055 & 4.311 & .000 & Supported \\
Trusting Attitudes $\rightarrow$ Tech. Attitudes $* * *$ & .163 & .048 & 3.749 & .000 & Supported \\
Tech. Attitudes $\rightarrow$ Intention $* * *$ & .645 & .033 & 17.000 & .000 & Supported \\
Trusting Attitudes $\rightarrow$ Intention $* * *$ & .269 & .032 & 8.123 & .000 & Supported \\
Subjective Norms $\rightarrow$ Intention*** & .131 & .046 & 4.196 & .000 & Supported \\
\hline
\end{tabular}

Note. Path significance: ${ }^{* * *} \mathrm{p}<.001 ; * \mathrm{p}<.05$ and ns: insignificant path.

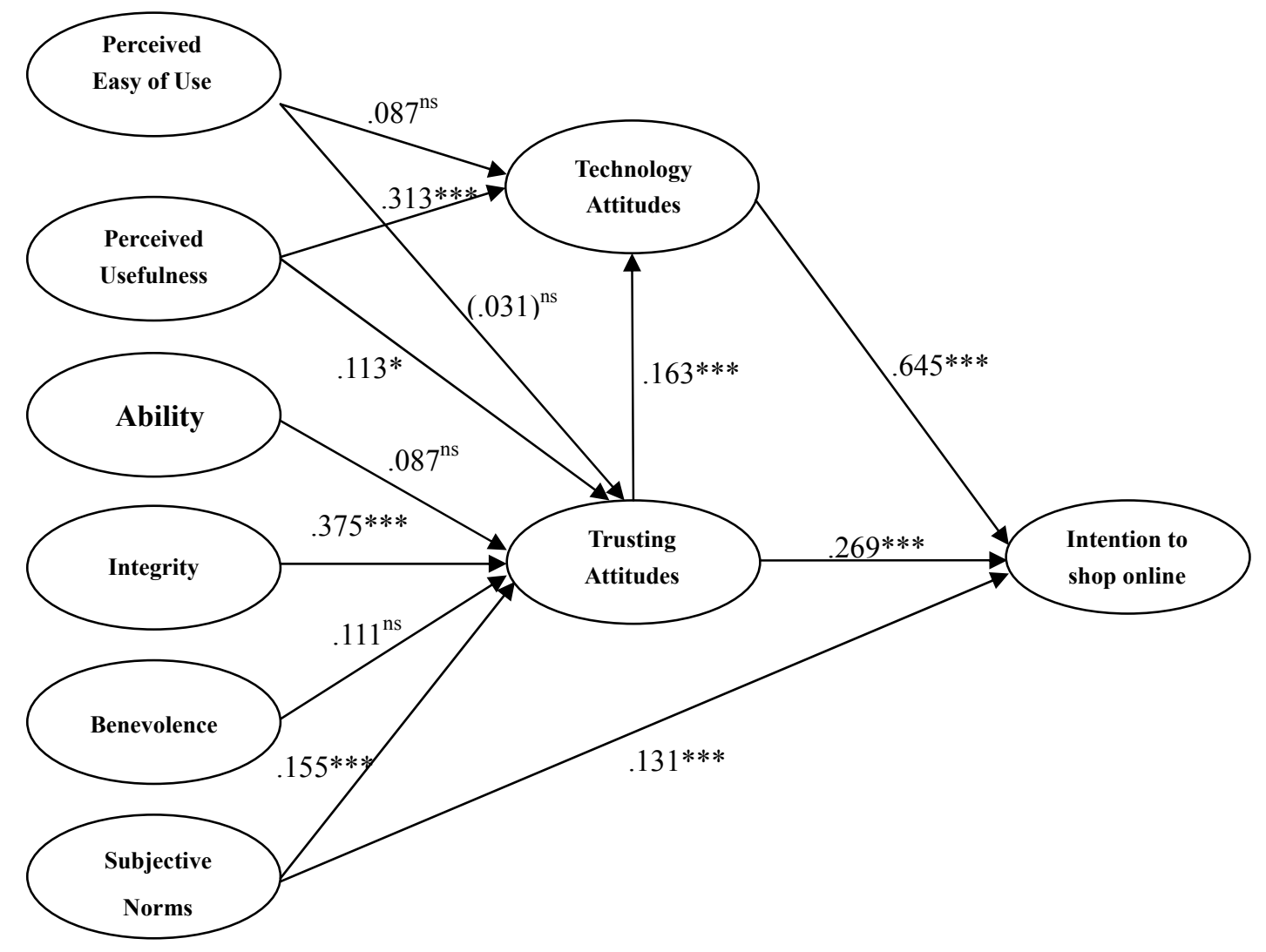

Figure 2. The result of structural model

Note. Path significance: ${ }^{* * *} \mathrm{p}<.001 ; * \mathrm{p}<.05$ and ns: insignificant path. 
Table 5. Result of mediating test for technology attitudes and trusting attitudes

\begin{tabular}{lccc}
\hline Relationships & Direct effect & Indirect effect & Total effect \\
\hline Perceived Usefulness $\rightarrow$ Intention to shop online & .308 & .227 & .536 \\
Subjective Norms $\rightarrow$ Intention to shop online & .124 & .053 & .177 \\
Integrity $\rightarrow$ Intention to shop online & $(.127)$ & .174 & .048 \\
\hline
\end{tabular}

Note. All paths are significant at level of .000.

\subsection{Discussion}

Overall, our model exhibited a reasonable fit with the data collected. $70.0 \%$ variance of consumers' intention to use online shopping is explained by technology beliefs, trusting beliefs and subjective norm beliefs with factor loading being $.645, .269$ and .131 , respectively. This result implies that all technology beliefs, trusting beliefs and subjective norm beliefs are as significant prediction factors on intention to use online shopping in the model.

For the sub-model of technology attitudes, it is very clear that the relationships between PEOU and PU, attitudes towards technology and intention to use online shopping have been significantly tested in many varieties of studies (McKnight et al., 2002; Van der Heijden et al., 2003; Lin, 2008). Using repeatedly hypotheses, the result of this study has reinforced a positive relationship among these constructs: perceived usefulness affects technology attitudes, which in turn affect the intention to use. However, most of previous studies in the context of information technology admitted a strong relationship between PEOU and technology attitudes, there was lack of support for a positive relationship between perceived ease of use and technology attitudes from the data collected. The result of this study also implies that technology beliefs (represented by perceived usefulness) are significant and indirect predictor of intentions to use online shopping through technology attitudes. This is supported bythe result found in the study of Gefen (Gefen, et al., 2003).

As for the sub-model of trusting attitudes, the results summarized in Table 4 and figure 2 shows that the specified relationships among ability, benevolence of online vendor and trusting attitudes were not supported by the data collected, whilst integrity of online vendor has a significant influence on trusting attitudes. This result is not in line with the findings found in some previous studies of trust in online shopping (McKnight et al., 2002; Cheung and Lee 2006; Benamati, Fuller et al. 2010). However, the relationship between integrity and trusting attitudes has been supported in some studies of electronic commerce (Morgan \& Hunt, 1994; Jarvenpaa \& Tiller, 2001).

Moreover, there is a significant existence of positive relationships among perceived usefulness, technology attitudes, subjective norm beliefs and trusting attitudes supported in this integrated research model. This is in line with the result of Benamati's study (Benamati et al., 2010). Notably, subjective norm beliefs are also pointed out as a main factor influencing positively trusting attitudes, which in turn, affect intention to shop online.

More important, the results in the table 5 suggested that technology beliefs (typically is perceived usefulness) be the strongest predictor for Vietnamese consumers' intention to shop online (total effect is .536). Following is subjective norm beliefs, which has explanatory power of intention to shop online with the total effect is .177. Even though trusting beliefs (typically is integrity of online vendors) has not a strong predictor in this model (total effect is .048), it is suggested that integrity is also considered as an important dimension of trust for explaining Vietnamese consumers' intention to use in the context of online shopping.

From the model results, it is confirmed that Vietnamese consumers' intention to adopt online shopping as a shopping medium is firstly explained by technology beliefs (perceived usefulness of their own using technology). It means that the higher consumers' perceived usefulness of online shopping is, the stronger their technology attitudes are and they become ready to adopt online shopping as a shopping medium. It is identified that, in fact, in the first phase of being in contact with online shopping, shoppers have a tendency to prefer to something new. They may be attracted by the immediate benefits of this shopping channel, so they may easily accept it as a shopping channel. Besides, this result also admitted the role of subjective norm beliefs towards Vietnamese consumers' trust in online shopping and its significant influence on their intention to use this shopping channel. In fact, it is very easy to identify that the effects of social norms of awareness and behavior of online consumers' behavior will be much more serious in the case of lacking empirical data about online shopping. In such cases, consumers tend to rely on the opinions of reliable people so as to assess information and select goods for making a transaction; choose online vendor as well as decide to buy via the Internet or not 
(Venkatesh \& Davis, 2000). Nonetheless, the significant existence of the relationship between integrity and intention to use online shopping one more confirmed that trusting beliefs is an important dimension of Vietnamese consumers' trust. Because of shopping in the virtue environment characterized by facelessness and intangibility, a host of concerns such as uncertainty, anonymity, lack of control and potential opportunism has plagued resulting in consumers' reluctance to engage in online transactions (Grabner-Kräuter \& Kaluscha, 2003). Hence, integrity of online vendor could be considered as a necessary condition toform Vietnamese consumers' trust in online shopping.

\section{Findings and Conclusions}

Motivated by the need to better understand the drivers of consumer trust affecting their intention to use Internet shopping, this research synthesized the three key theoretical perspectives of trust (technology beliefs, trusting beliefs and subjective norm beliefs) and developed an integrative model for explaining the role of consumer trust to continuously shop online. Importantly, a main purpose of this study was to develop and empirically test a model of Vietnamese consumers' trust towards the intention to adopt online shopping. The findings of this study indicate that the research model explaining the role of trust towards Vietnamese consumers' intention to use online shopping is acceptable, in which, perceived usefulness is the strongest factor affecting Vietnamese consumers' intention to use online shopping. Out of technology beliefs, trusting beliefs (typically is integrity of online vendor) and especially subjective norm beliefs are also identified as important antecedents affecting Vietnamese consumers' intention to use online shopping. Hence, the findings of this study are noteworthy for both researchers and practitioners. Based on the result of a qualitative study aforetime conducted, this study has developed and empirically tested an integrative model for explaining the role of Vietnamese consumers' trust in their intention to use E-commerce as a shopping medium. The finding is an evidence for a more holistic explanation and confirmation of the role of Vietnamese consumers' trust towards their intention to use E-commerce. Specifically, the measurement model is confirmed with adequate convergent and discriminant validity of all measures. The structural model provides a highly significant percentage of variance explained $(70.0 \%)$. What is more, our study has also pointed out a significant contribution and effect level of perceived usefulness, integrity of online vendor and subjective norms in explaining Vietnamese consumers' trust towards intention to shop online. This information should prove to be particularly useful to $\mathrm{B} 2 \mathrm{C}$ e-commerce decision makers in Vietnam.

\section{Limitations and Implications}

Apart from the contributions, there are still limitations in this research. Objectively, the study was conducted when online shopping in Vietnam was in its rag and spontaneous development by individuals without a close legislative control causing risks for online consumers doing transactions in this market. Therefore, trust is a sensitive topic to be measured accurately. Furthermore, investigating on a large-scaled geographical distribution through online survey, the researchers could not have full control of informants' biases while they were answering the questionnaire. Therefore, the results found in this study cannot fully reflect Vietnamese consumers' opinions on online shopping. Subjectively as the survey was conducted employing snowball technique, informants shared similarities in their social figures and opinions; in fact, there was a mutual impact among those opinions as they were tightened in the previous existing relationships.

Implications for researchers: Trust is an interesting but sensitive topic, especially when it is studied in Vietnamese market where there is a lack of trust in both brick and mortar environment and online shopping. Accordingly to get a more objective and accurate result, random sampling technique applied on a variety of informants would be necessary gaining a more sufficient insight into consumers' viewpoint on online shopping as well as the role of trust in the intention to use this shopping channel. In addition, researchers should also anticipate informants' biases to design and combine various suitable techniques to collect relevant data in order to control and minimize informants' biases. Moreover, trust is a complex psychological category and the formation of trust varies among different consumers. Further study should be conducted to explain how the difference in trust among different consumers (gender, age, experience...), website typesand even with different kinds of goods.

Besides, the proposed model in this study mainly focus on valuating the role of trust affecting Vietnamese consumer's intention to use online shopping. Presently, the model has not yet considered evaluating the roles of other variables in Vietnamese consumers' intention to adopt online shopping. For instance, the model does not consider the typology of goods and/or service purchased, online vendor's reputation and prestige, online consumers' characteristic and so on. In addition, in virtual markets, online transaction costs are low (thanks to search engines and electronic price comparisons); market transparency and competition are high. Therefore, a 
further research should be conducted with the consideration of the above variables added in the proposed model in order to fully explaining Vietnamese consumers' intention to shop online.

Notably, the research is limited only to the cluster of online shoppers to explain the role of trust beliefs towards consumers' intention to shop online that these individuals have alreadypartly showed a positive attitude towards intention to use e-commerce. Hence, an extended analysis to the cluster of both online shoppers and conventional shoppers with the combination of usingother qualitative methods in order to identify which are the main barriers to e-commerce usage should be done in the future research development.

Implications for practitioners: This study has pointed out the role of perceived usefulness of online shopping, integrity of online vendors and subjective norms in explaining the acceptance of online shopping as a shopping channel. This result implies a message to managers in the field of E-commerce. First of all, the habit of 'see it, feel it' has rooted in Vietnamese consumers' consciousness; in order to change this habit the managers should have in mind that consumers can only be ready for online shopping when they believe that they can get more benefits from this shopping channel compared with the traditional one. Secondly, as transactions in online shopping are made without any direct contact between consumers and providers, Vietnamese consumers are ready for online shopping only when the online vendors are prestigious fulfilling their commitments and responsibilities in the transactions. Thirdly, in the age of information technology where information can be strongly distributed on E-newspapers and social networks, community plays a vital role having impact on the consumption habit and behaviour of consumers as it does in Vietnam. As a result, building prestige for the providers themselves is necessary to establish and reinforce consumers' trust in adopting online shopping. It can be seen that the providers' prestige is a strong PR tool in the context where society has been affirmed to have strong impact in the community of Vietnamese consumers.

\section{Acknowledgment}

The authors wish to thank the Editor and anonymous reviewers for their helpful comments and suggestions. The work described in this paper was supported by a grant from the National Nature Science Foundation of Chinese (project no. NSFC 71272177/G020902) and the funds of "Innovation Program of Shanghai Municipal Education Commission" (project no.12ZS101).

\section{References}

Ahn, T., S., \& Ryu. (2004). The impact of the online and offline features on the user acceptance of Internet shopping malls. Electronic Commerce Research and Applications, 3(4), 405-420. http://dx.doi.org/10.1016/j.elerap.2004.05.001

Ahn, T. S., \& Ryu. (2007). The impact of Web quality and playfulness on user acceptance of online retailing. Information \& Management, 44(3), 263-275. http://dx.doi.org/10.1016/j.im.2006.12.008

Benamati, J. M., \& Fuller. (2010). Clarifying the integration of trust and TAM in e-commerce environments: implications for systems design and management. Engineering Management, IEEE Transactions, 57(3), 380-393. http://dx.doi.org/10.1109/TEM.2009.2023111

Browne, M. W. R., \& Cudeck. (1993). Alternative ways of assessing model fit. Sage Focus Editions, 154, $136-136$.

Çelik, H. (2011). Influence of social norms, perceived playfulness and online shopping anxiety on customers' adoption of online retail shopping: An empirical study in the Turkish context. International Journal of Retail \& Distribution Management, 39(6), 390-413. http://dx.doi.org/10.1108/09590551111137967

Çelik, H. E., \& Veysel, Y. (2011). Extending the Technology Acceptance Model for adoption of E-Shopping by Consumers in Turkey. Journal of Electronic Commerce Research, 12(2), 152-164.

Chen, S. C., \& Dhillon, G. S. (2003). Interpreting dimensions of consumer trust in e-commerce. Information Technology and Management, 4(2), 303-318. http://dx.doi.org/10.1023/A:1022962631249

Chen, S. J., \& Chang, T. Z. (2003). A descriptive model of online shopping process: some empirical results. International Journal of Service Industry Management, 14(5), 556-569. http://dx.doi.org/10.1108/09564230310500228

Cheung, C. M. K., \& Lee, M. K. O. (2003). An integrative model of consumer trust in internet shopping. European Conference on Information Systems (ECIS), Naples, Italy.

Cheung, C. M. K., \& Lee, M. K. O. (2006). Understanding consumer trust in Internet shopping: A multidisciplinary approach. Journal of the American Society for Information Science and Technology, 57(4), 
479-492. http://dx.doi.org/10.1002/asi.20312

Corbitt, B. J. T., \& Thanasankit. (2003). Trust and e-commerce: a study of consumer perceptions. Electronic Commerce Research and Applications, 2(3), 203-215. http://dx.doi.org/10.1016/S1567-4223(03)00024-3

Davis, F. D. (1989). Perceived usefulness, perceived ease of use, and user acceptance of information technology. MIS Quarterly, 319-340. http://dx.doi.org/10.2307/249008

Fornell, C., \& Larcker, D. F. (1981). Evaluating structural equation models with unobservable variables and measurement error. Journal of Marketing Research, 39-50. http://dx.doi.org/10.2307/3151312

Gefen, D. (2000). E-commerce: the role of familiarity and trust. Omega, 28(6), 725-737. http://dx.doi.org/10.1016/S0305-0483(00)00021-9

Gefen, D. (2002). Reflections on the dimensions of trust and trustworthiness among online consumers. $A C M$ SIGMIS Database, 33(3), 38-53. http://dx.doi.org/10.1145/569905.569910

Gefen, D., \& Karahanna, E. (2003). Trust and TAM in online shopping: An integrated model. MIS Quarterly, 51-90.

Grabner-Kräuter, S., \& Kaluscha, E. A. (2003). Empirical research in on-line trust: a review and critical assessment. International Journal of Human-Computer Studies, 58(6), 783-812. http://dx.doi.org/10.1016/S1071-5819(03)00043-0

Ha, S., \& Stoel, L. (2009). Consumer e-shopping acceptance: Antecedents in a technology acceptance model. Journal of Business Research, 62(5), 565-571. http://dx.doi.org/10.1016/j.jbusres.2008.06.016

Hair, J. F., \& Anderson, R. E. (1998). Multivariate data analysis. Upper Saddle River, NJ: Prentice Hall.

Ho, T. H. L., \& Chen, Y. (2013). Vietnamese consumers' intention to online shopping adoption: A qualitative approach. World, 2(3).

Holsapple, C. W., \& Sasidharan, S. (2005). The dynamics of trust in B2C e-commerce: a research model and agenda. Information Systems and E-Business Management, 3(4), 377-403. http://dx.doi.org/10.1007/s10257-005-0022-5

Jarvenpaa, S. L., \& Tiller, E. H. (2001). Customer trust in virtual environments: A managerial perspective. BUL Rev, 81, 665 .

Jayawardhena, C., \& Wright, L. T. (2009). An empirical investigation into e-shopping excitement: antecedents and effects. European Journal of Marketing, 43(9/10), 1171-1187. http://dx.doi.org/10.1108/03090560910976429

Kim, D. J., \& Ferrin,D. L. (2008). A trust-based consumer decision-making model in electronic commerce: The role of trust, perceived risk, and their antecedents. Decision Support Systems, 44(2), 544-564. http://dx.doi.org/10.1016/j.dss.2007.07.001

Koufaris, M., \& Hampton-Sosa, W. (2004). The development of initial trust in an online company by new customers. Information \& Management, 41(3), 377-397. http://dx.doi.org/10.1016/j.im.2003.08.004

Lei, P. W., \& Wu, Q. (2007). Introduction to structural equation modeling: Issues and practical considerations. Educational Measurement: Issues and Practice, 26(3), 33-43. http://dx.doi.org/10.1111/j.1745-3992.2007.00099.x

Lin, H. F. (2008). Predicting consumer intentions to shop online: An empirical test of competing theories. Electronic Commerce Research and Applications, 6(4), 433-442. http://dx.doi.org/10.1016/j.elerap.2007.02.002

McKnight, D. H., \& Choudhury, V. (2002). Developing and validating trust measures for e-commerce: An integrative typology. Information Systems Research, 13(3), 334-359. http://dx.doi.org/10.1287/isre.13.3.334.81

Moon, J. W., \& Kim, Y. G. (2001). Extending the TAM for a World-Wide-Web context. Information \& Management, 38(4), 217-230. http://dx.doi.org/10.1016/S0378-7206(00)00061-6

Morgan, R. M., \& Hunt, S. D. (1994). The commitment-trust theory of relationship marketing. Journal of Marketing, 20-38. http://dx.doi.org/10.2307/1252308

Nunnally, J. C., \& Bernstein, I. H. (1991). Psychometric theory. New York: McGraw.

Pavlou, P. A., \& Fygenson, M. (2006). Understanding and predicting electronic commerce adoption: An 
extension of the theory of planned behavior. MIS Quarterly, 115-143.

Rivis, A., \& Sheeran, P. (2003). Descriptive norms as an additional predictor in the theory of planned behaviour: A meta-analysis. Current Psychology, 22(3), 218-233. http://dx.doi.org/10.1007/s12144-003-1018-2

Schepers, J., \& Wetzels, M. (2007). A meta-analysis of the technology acceptance model: Investigating subjective norm and moderation effects. Information \& Management, 44(1), 90-103. http://dx.doi.org/10.1016/j.im.2006.10.007

Schreiber, J. B., \& Nora, A. (2006). Reporting structural equation modeling and confirmatory factor analysis results: A review. The Journal of Educational Research, 99(6), 323-338. http://dx.doi.org/10.3200/JOER.99.6.323-338

Van der Heijden, H., \& Verhagen, T. (2003). Understanding online purchase intentions: contributions from technology and trust perspectives. European Journal of Information Systems, 12(1), 41-48. http://dx.doi.org/10.1057/palgrave.ejis.3000445

Venkatesh, V., \& Bala, H. (2008). Technology acceptance model 3 and a research agenda on interventions. Decision Sciences, 39(2), 273-315. http://dx.doi.org/10.1111/j.1540-5915.2008.00192.x

Venkatesh, V., \& Davis, F. D. (2000). A theoretical extension of the technology acceptance model: Four longitudinal field studies. Management Science, 46(2), 186-204. http://dx.doi.org/10.1287/mnsc.46.2.186.11926

Venkatesh, V., \& Morris, M. G. (2000). Why don't men ever stop to ask for directions? Gender, social influence, and their role in technology acceptance and usage behavior. Management Information Systems Quarterly, 24(1), 115-140. http://dx.doi.org/10.2307/3250981

Venkatesh, V., \& Morris, M. G. (2003). User acceptance of information technology: Toward a unified view. MIS Quarterly, 425-478.

Vijayasarathy, L. R. (2004). Predicting consumer intentions to use on-line shopping: the case for an augmented technology acceptance model. Information \& Management, 41(6), 747-762. http://dx.doi.org/10.1016/j.im.2003.08.011

\section{Appendix}

\section{STUDY QUESTIONS}

Perceived Ease of use

a. It is easy for me to learn how to use online shopping, even as the first time.

b. It will be impossible to make an online transaction without expert help.

c. Using online shopping do not requires a lot of mental effort.

d. It is easy for me to become skillful at using online shopping.

Perceived Usefulness

a. "Online shopping" is useful to search and buy something I need.

b. Using online shopping enables me to search and buy something more quickly.

c. Using online shopping helps me to get better purchasing decision.

d. Using online shopping improves my task quality.

e. Using online shopping increases my task productivity.

Ability

a. Online vendors have the necessary technology knowledge to carry out the online transaction.

b. Online vendors have the necessary skill and ability to carry out the online transaction.

c. Online vendors have sufficient resources to carry out the online transaction.

d. The change of having a technical failure in an online transaction is quite small.

e. Technology obstacles should not be a major concern when conducting online transactions.

f. Online vendors have an expertise to do online transaction. 


\section{Integrity}

a. Online vendor always provides reliable information.

b. Online vendor always provides plausible commitments.

c. Online vendor always keeps their promises and commitments.

d. I believe in online vendor' advices and warnings.

e. I do not doubt the online vendor's honesty.

\section{Benevolence}

a. Online vendor always concerns customers' needs.

b. Online vendor always keeps customers' best interests in mind.

c. Online vendor has no unrighteous interests motivation.

d. Online vendor would do the job right even if not monitored.

e. Online vendor always meet customers' expectations and needs.

\section{Subjective Norms}

a. Peoplewho are important to me would think that I should use online shopping.

b. People who are important to me would encourage me to use online shopping.

c.People who influence my behavior would think that I should use online shopping.

d. People who influence my behavior would encourage me to use online shopping.

e.I often tend tochoose an online vendor of which transactions has been doneby a large number of shoppers.

f. I often buy what I need via the Internet that it is appreciated by experienced shoppers.

Trusting attitudes (Attitudes towards online vendor)

a. If I needed to buy something in a hurry, I would feel comfortable depending on website that I have frequently used.

b. I feel that I could count on website that I have frequently used to help me purchase something I need.

c. If I needed the best item on a specific product line, I would be willing to rely on the information provided by online vendor.

Technology Attitudes (Attitudes to use online shopping)

a. Using online shopping is a good idea.

b. Using online shopping is a wise idea.

c. Using online shopping is pleasant idea.

d. Using online shopping is a positive idea.

e. Using online shopping is an appealing idea.

Intention to use online shopping

a. I will keep using online shopping in the future.

b. I will frequently use online shopping as a shopping medium in the future.

c. I will frequently use online shopping rather than traditional one for purchasing product in the future.

d. I will recommend others to use online shopping.

\section{Copyrights}

Copyright for this article is retained by the author(s), with first publication rights granted to the journal.

This is an open-access article distributed under the terms and conditions of the Creative Commons Attribution license (http://creativecommons.org/licenses/by/3.0/). 